\title{
Privacidade do usuário na atividade de busca: o caso do Arquivo Público do Estado de São Paulo
}

\section{Paula Regina Ventura Amorim Gonçalez}

Bacharel em Biblioteconomia e mestre em Ciência da Informação pela UNESP Doutoranda do Programa de Pós-Graduação em Ciência da Informação da Faculdade de Filosofia e Ciência Universidade Estadual Paulista - UNESP, Campus Marília

Ricardo César Gonçalves Santana

Doutor em Ciência da Informação pela UNESP. Professor do Programa de Pós Graduação em Ciência da Informação da Faculdade de Filosofia e Ciência - Universidade Estadual Paulista UNESP, Campus Marília

Maria José Vicentini Jorente

Doutora em Ciência da Informação pela UNESP. Professora do Programa de Pós Graduação em Ciência da Informação da Faculdade de Filosofia e Ciência - Universidade Estadual Paulista UNESP, Campus Marília

http://dx.doi.org/10.1590/1981-5344/2372

Com o advento da Internet tornou-se possível superar os espaços temporais, havendo um ganho no conhecimento ao identificarmos que dificilmente as informações disponíveis seriam acessadas por um número de usuários potencialmente ampliado pelo uso das Tecnologias de Informação e Comunicação. A partir do ano de 2003, diante dessas novas possibilidades o Arquivo Público do Estado de São Paulo, ampliou sua forma de atuação ao disponibilizar parte de seu acervo documental no ambiente Web, disseminando informações arquivísticas e tornando-as acessíveis. A popularização da Internet e as políticas públicas de acesso à informação que garantem a todo cidadão tal direito por meio da Lei de Acesso à Informação nortearam este estudo que objetivou a aplicação do Framework para análise de privacidade, apresentado por Rubel e Biava (2014) no acesso à informação nos ambientes do Arquivo Público do Estado de São Paulo. A metodologia consistiu em uma 
investigação teórica baseada nos princípios de privacidade na ambiência física e digital e exploratório a partir da visita e da observação do referido arquivo em seus ambientes físicos e digitais. Verificou-se como resultado que o uso do framework possibilita conhecer problemas de complexidade variada quanto ao grau de privacidade dos usuários nos diferentes ambientes.

Palavras-chave: Arquivos Permanentes; Web; Informação e Tecnologia; Privacidade

\section{User privacy in search activity: the case of the Public Archives of the State of São Paulo}

With the advent of the Internet, it has become possible to overcome timelines with a gain in knowledge by identifying that information available were seldomly accessed by a number of potentially expanded users through the use of Information and Communication Technologies. From the year 2003, before these new possibilities, the Public Archives of the State of São Paulo magnified the way it operates to provide part of its collection of documents on the Web environment, disseminating archival information and making them accessible. The popularization of the Internet and the public policies that guarantee access to information for all citizens through the Access to Information Act. Guided this study, aimed towards the application of Framework for privacy analysis, presented by Rubel and Biava (2014) on access to information in the environments of Public Archives of the state of São Paulo. The methodology consisted of a theoretical investigation based on the principles of privacy in the physical, exploratory and digital environment, and from the visit and observation of said file in its physical and digital environments. As a result, it was found that the use of framework allows understanding of varying complexity problems in the degree of privacy of users in different environments.

Keywords: Permanent Archives; Web; Information Technology; Privacy. 


\section{Introdução}

A ampliação e a intensificação do uso das Tecnologias de Informação e Comunicação e da globalização favoreceram o crescimento do acesso e uso de informações disponíveis. Assim, além do tratamento adequado das informações registradas para que seu acesso, recuperação, uso preservação e reuso se tornem facilitados, surge a preocupação com a privacidade dos dados de quem as acessa, ao mesmo tempo em que é requerida a transparência no formato das informações disponibilizadas.

Grande parte dos documentos está armazenada também na ambiência digital e na Web para uma disseminação de forma extensiva. Nesse contexto, aumentam-se as indagações quando são levantadas questões sobre o direito à privacidade a partir dos avanços tecnológicos, da possibilidade de acesso às informações pessoais, bem como a utilização de tais informações.

É indiscutível o papel da informação na sociedade contemporânea, visto que, a sociedade da informação se configura como principal traço dos debates públicos sejam eles locais ou globais.

Para Werthein (2000, p. 71) a expressão Sociedade da Informação,

[...] passou a ser utilizada, nos últimos anos desse século, como substituto para o conceito complexo de 'sociedade pósindustrial' e como forma de transmitir o conteúdo específico do 'novo paradigma técnico-econômico'.

Nesse contexto, a sociedade da informação tem se consolidado a partir das inúmeras possibilidades de acesso à informação propiciada pela evolução tecnológica, que teve início com a diversificação dos suportes da informação e passam a fazer parte dos acervos outros tipos de registros informacionais como fotos, gravações de áudio/vídeo e programa de computadores entre outras, culminando com a revolução dos computadores e das tecnologias de rede e telecomunicações, pois, coleções totalmente digitais passaram a serem construídas e digitalizadas.

Alvarenga (2003, p. 2), pontua que, quando refletimos sobre o advento das tecnologias e seu uso intensivo na perspectiva da ciência da informação,

[...] constata-se positiva turbulência no campo de conhecimento, especialmente no que tange à representação, à armazenagem e a recuperação de informações, áreas intensamente relacionadas a cognição humana. As peculiaridades da organização do conhecimento nas vertentes que costumam ser identificadas como integrantes do escopo da ciência da informação - a arquivologia, a biblioteconomia e a museologia.

Com o aumento da capacidade dos computadores, surge a Word Wide Web e com a velocidade das redes, repositórios de informação são 
construídos possibilitando o acesso e compartilhamento do conteúdo dos documentos que estão em formato digital.

Para Castells (1999, p. 375)

[...] a tecnologia digital permitiu a compactação de todos os tipos de mensagens, inclusive sons, imagens e dados, formouse uma rede capaz de comunicar todas as espécies de símbolos... A universalidade da linguagem digital e a lógica pura de sistema de comunicação em rede criaram as condições tecnológicas para a comunicação horizontal global.

As Tecnologias de Informação e Comunicação estão se desenvolvendo e determinando transformações no universo informacional em todas as áreas do conhecimento humano, a informação vem alcançando status cada dia mais importante.

Assim, ela se torna insumo para viabilização das atividades nos processos: culturais, de ensino e aprendizagem, na aquisição e construção do conhecimento para a pesquisa científica e tecnológica e em outros setores ou atividades onde é necessário o conhecimento humano (MARCONDES, 2001) e no mundo dos negócios, quando empresários percebem que problemas de negócio são na verdade, problemas de informação (ROSENFELD, 2002).

Nesse momento nosso contexto social é evidenciado pela rapidez da evolução das TIC, potencializam-se as discussões concernentes à privacidade, ao direito ao esquecimento e a transparência com que as informações são tratadas e disponibilizadas tanto no meio físico como no meio virtual.

Este estudo objetivou analisar e comparar os estados de privacidade dos usuários do Arquivo Público do Estado de São Paulo, que fazem suas pesquisas indo ao seu local físico ou acessando seu site através de um terminal de computador. Para tanto foi considerado o Framework para análise de privacidade, apresentado por Rubel e Biava (2014).

A investigação teórica foi baseada nos princípios de privacidade na ambiência física e digital a exploratória foi realizada a partir da visita e da observação do referido arquivo em seus ambientes físicos e digitais e na aplicação do Framework para análise e comparação da privacidade (RUBEL; BIAVA, 1014).

\section{Privacidade, arquivos públicos e as tecnologias de informação e comunicação}

O acesso e a divulgação das informações relacionadas à vida privada das pessoas, a partir do uso das novas tecnologias e dos instrumentos tecnológicos que passam a fazer parte do cotidiano do indivíduo intensificam os debates sobre o direito à privacidade.

O início dessa preocupação foi sentida em 1890 quando, Warrem e Bradeis, publicam o primeiro artigo sobre privacidade na Harvard Law 
Review "The Right to Privacy", em que os autores apontavam a maneira na qual a fotografia, os jornais e os aparatos móveis invadiam a vida doméstica e privada das pessoas.

Em dias atuais discussões sobre o direito à privacidade tanto dos dados como do sujeito que os buscam, tem se tornado recorrente. 0 conceito de privacidade devido a sua complexidade é de difícil definição, por esse motivo, tem sido discutido como um problema social na era da informação, visto que, envolve questões subjetivas e está relacionado ao indivíduo e à dignidade humana.

Como Instituição responsável pela organização, pelo tratamento, pela custódia, pela preservação e disseminação dos acervos, os arquivos públicos se configuram como espaços ou lugares de memória coletiva, que mantem e conservam documentos e propiciam meios para o acesso e recuperação dos documentos e/ou informações.

O Arquivo sendo compreendido como um espaço público de construção da cidadania, e a ideia de acesso à informação, foi regulamentada por intermédio da Lei no 8.159 - de 08 de Janeiro de 1991 (BRASIL. Presidência da República, 1991).

Art.10 É dever do poder público a gestão documental e a proteção especial a documentos de arquivos, como apoio à administração, à cultura, ao desenvolvimento científico e como elementos de prova e informação.

Art.20 Consideram-se arquivos, para os fins desta lei, os conjuntos de documentos produzidos e recebidos por órgãos públicos, instituições de caráter público e entidades privadas, em decorrência do exercício de atividades informação ou a natureza dos documentos.

Para o Conselho Nacional de Arquivos (CONARQ, 2009, p. 164), arquivo pode ser definido como:

1 Conjunto de documentos produzidos e acumulados por uma entidade coletiva, pública ou privada, pessoa ou família, no desempenho de suas atividades, independentemente da natureza dos suportes.

2 Instituição ou serviço que tem por finalidade a custódia, o processamento técnico, a conservação e o acesso a documentos arquivísticos.

Segundo Bellotto (2005, p. 20), o arquivo é formado por um conjunto indivisível de documentos, desta forma, o princípio da indivisibilidade ou integridade arquivística, propõe a "preservação dos fundos de arquivo sem dispersão, mutilação, alienação, destruição não autorizada ou adição indevida". 
O Conarq é o órgão colegiado, vinculado ao Arquivo Nacional do Ministério da Justiça no Brasil e que define a política nacional de arquivos públicos e privados exercendo orientação normativa visando a gestão documental e a proteção especial aos documentos de arquivo.

As Tecnologias de Informação e Comunicação impactaram as ações humanas, inovaram os canais e os instrumentos de comunicação e a partir do uso das novas tecnologias da informação, os meios de comunicação e também as novas formas de produção documental nortearam a arquivologia a repensar em seus conceitos e princípios, e também no papel dos arquivistas e dos arquivos na sociedade da informação.

\subsection{Arquivo Público do Estado de São Paulo}

O Arquivo Público do Estado de São Paulo, uma das repartições públicas mais antigas da cidade de São Paulo, tem suas origens por volta de 1721 e vem se consolidando como uma importante fonte para as pesquisas documentais do Brasil e referência na historiografia brasileira. Abrigam aproximadamente 26 mil metros lineares de documentação textual, em seu acervo iconográfico têm por volta de um milhão e meio de imagens e milhares de rolos de microfilmes, uma biblioteca com 45 mil volumes, mapoteca e hemeroteca.

Buscando propiciar o acesso à informação agora garantido a todo cidadão pela Lei no 12.527 de 18 de novembro de 2011 - Lei de Acesso (BRASIL. Presidência da República, 2011), o Arquivo Público do Estado de São Paulo, desde setembro 2003, se faz presente na ambiência digital por meio de seu site http://www.arquivoestado.sp.gov.br/, passando a atender os usuários não somente de maneira presencial como também de forma remota.

\section{Comparação de estados de privacidade}

Frente às discussões sobre o direito e proteção à privacidade de dados e informações, para que pudéssemos conhecer e comparar a privacidade e a proteção da privacidade dos usuários que procuram o arquivo público do Estado de São Paulo de maneira presencial ou remota utilizou-se o framework, proposto pelos autores Rubel e Biava (2014): A Framework for analyzing and comparing privacy states.

Para Rubel e Biava (2014, p. 1, tradução nossa), essa é: "uma linha de investigação que se refere a fatores contextuais que afetam as proteções de privacidade e direitos de privacidade". Dessa maneira, os autores propõem um quadro e a base conceitual, para que possa ser definido e identificado os aspectos de privacidade e de seu contexto, e analisada a privacidade, a proteção à privacidade e os direitos à privacidade.

Com a utilização da estrutura de tal framework, tem se a possibilidade não somente de identificar e descrever com precisão os aspectos particulares de privacidade e os contextos da privacidade, comparando a privacidade em diferentes situações, considerando variáveis 
como o tempo, a localização e a política, como também, nos oferece um vocabulário flexível e notação para facilitar as descrições e comparações.

Baseando-se em considerações particulares e concepções de privacidade, o quadro pode acomodar de maneira coerente uma grande variedade de concepções e critérios de delimitações para a privacidade.

Porém, a privacidade deve ser entendida como uma relação de três partes, em que ele articula as partes relevantes de forma diferente (RUBEL, 2011).

Sob este ponto de vista, Rubel (2011, p. 278-79, tradução nossa) pontuam que:

[...] qualquer instância de privacidade deve envolver: alguma pessoa ou pessoas $P$, algum domínio de informações $O$, e qualquer outra pessoa ou pessoas $Q$. Sendo que: para $P$ (pessoa ou pessoas) ter privacidade em relação a O (Domínio de informação) em relação a $Q$ (qualquer outra pessoa ou pessoas) e para que $Q$ (qualquer outra pessoa ou pessoas) não tenha capacidade de fazer julgamentos particularizados razoáveis sobre $\mathrm{P}$ (pessoa ou pessoas), o $\mathrm{O}$ (domínio da informação) deve ser limitado.

A partir da expressão $P O Q$, pode-se denotar qualquer instância de privacidade ou estado de intimidade. Conforme mencionado anteriormente ainda não há um consenso sobre como definir privacidade, porém do ponto de vista predominante na literatura é de que a privacidade é fundamental sobre o acesso e ao controle da informação. Para as contas de acesso, a privacidade baseia-se em saber se outras pessoas tem acesso de maneira física ou cognitiva, ou se o acesso acontece das duas maneiras.

Para facilitar a representação dos diferentes tipos de privacidade, Rubel e Biava (2014, p.4) propõem a Tabela 1, pois entendem que Privacidade é normalmente entendida como a capacidade de um indivíduo para restringir os fluxos de informação sobre elas para outras pessoas.

Tabela 1 - Representação de diferentes tipos de privacidade

\begin{tabular}{l|l}
\hline Concepção de privacidade & Símbolo associado \\
\hline \hline Acesso & $\alpha$ \\
\hline Controle & $\kappa$ \\
\hline Julgamento particularizado & $\pi$ \\
\hline Conhecimento & $v$ \\
\hline
\end{tabular}

Fonte: RUBEL; BIAVA (2014, p. 4, tradução nossa).

Desta forma, $\boldsymbol{a}$ representam uma conta de acesso de privacidade.

E, $\boldsymbol{a}$ PoQ representam as três partes da privacidade ( $P$ alguma pessoa ou pessoas, $O$ algum domínio de informações e $Q$ qualquer outra pessoa). 
Os autores apontam que, apesar da variação entre as concepções de privacidade, cada tipo pode ser entendido como um termo de uma relação de três partes. Deve-se apenas especificar o que as três partes $P O Q$ da relação denota (controle, acesso, conhecimento, julgamentos particularizados e assim por diante).

Descrevem ainda, sobre a natureza da privacidade e fixam um meio de denotar as relações de privacidade $P O Q$. Dessa maneira nos é permitido descrever um estado de privacidade de forma isolada.

A representação das concepções particulares de privacidade poderá ser obtida em qualquer relação $P O Q$.

Para analisar e comparar a privacidade dos usuários do Arquivo Público do Estado São Paulo que fazem suas buscas no acervo de maneira presencial ou remota, utilizou-se a representação de acesso $\boldsymbol{a}$ do Framework proposto por Rubel e Biava (2014).

Tendo em vista que em dias atuais o acesso à informação pública se tornou regra, e o sigilo é a exceção, procura-se diminuir e até mesmo superar a cultura do sigilo e, por conseguinte, criar a cultura do acesso, ampliando a disponibilização informações documentais e propiciando o acesso aos documentos através da Web, salvo as exceções já previstas em lei (GONÇALEZ, 2013) e busca-se o ponto entre o acesso e o respeito à privacidade de quem necessite da informação.

Pautados na Lei federal no 12.527de 18 de novembro de 2011, que regulamenta o direito constitucional de acesso à informação pública, que em seu capítulo III, do procedimento de acesso à informação, seção I, Do Pedido de Acesso em seu Art. 10, está estabelecido o seguinte apontamento:

Qualquer interessado poderá apresentar pedido de acesso a informações aos órgãos e entidades referidos no art. 10 desta Lei, por qualquer meio legítimo, devendo o pedido conter a identificação do requerente e a especificação da informação requerida.

§ 10 Para o acesso a informações de interesse público, a identificação do requerente não pode conter exigências que inviabilizem a solicitação.

Devido à pesquisa ser realizada no Arquivo Público do Estado de São Paulo, buscou-se o Decreto no 58.052, de 16 de maio de 2012 (BRASIL. Presidência da República, 2012), que regulamenta a Lei Federal no 12.527, de 18 de novembro de 2011 (BRASIL. Presidência da República, 2011), pelo então Governador Geraldo Alckmin, que em sua Seção IV, Do Pedido, em seu Artigo 14, trás o seguinte texto:

O pedido de informação deverá ser apresentado ao Serviço de Informação ao Cidadão - SIC do órgão ou entidade, por qualquer meio legítimo que contenha a identificação do interessado (nome, número de documento e endereço) e a especificação da informação requerida. 
Nesses dois apontamentos da lei, entende-se que esta contempla o pedido formal, que se dá por intermédio de um órgão governamental, que em São Paulo é o SIC.

Já quando se trata especificamente do acesso à informação de maneira remota o Conarq, ao proporem as Diretrizes Gerais para a Construção de Websites de Instituições Arquivísticas (2000, p. 6-7), em seu item 4.3 Desenho e Estrutura, afirmam que: "Acessibilidade e facilidade de navegação no website devem ser privilegiadas, oferecendose ao usuário informações". E entre outros apontamentos recomendam que os sites das instituições arquivísticas, devem oferecer "Garantias de segurança no acesso quando da tramitação de dados, especialmente os de caráter sigiloso ou aqueles relativos à privacidade do usuário".

Diante do exposto, procura-se analisar se ao ser feita a mediação e a comunicação do conhecimento ao usuário que procura o Arquivo Público do Estado de São Paulo de maneira presencial ou remota podemos aplicar o framework para análise e comparação de estados de privacidade proposto por Rubel e Biava (2014).

\section{Narrativa de acesso}

A partir de visita presencial às dependências do Arquivo Público do Estado de São Paulo e também da visita remota em sua página na Web, pudemos verificar como se dá o acesso aos dados e às informações arquivísticas, bem como, de que maneira é tratada a privacidade do usuário que faz suas buscas no ambiente físico ou digital.

O Arquivo Público do Estado de São Paulo se localiza a Rua Voluntários da Pátria, 596 no bairro de Santana na cidade de São Paulo com atendimento ao público de segunda à sexta-feira, das 9 às $17 \mathrm{~h}$, porém, os pedidos deverão ser feitos até às $16 \mathrm{~h}$.

Para que pudéssemos fazer a consulta de maneira presencial escolhemos os documentos Ostensivos, isto é, aqueles que não lhe foi atribuído nenhum grau de sigilo, o acesso ao seu conteúdo não põe em riscos direitos individuais ou coletivos e o acesso a esses documentos é um direito constitucional atribuído por lei.

Já no acesso remoto, para que pudéssemos conhecer as informações referentes à privacidade do usuário, visto que, quando é acessada pelo usuário uma informação disponível no site, não se faz necessário sua identificação, utilizou-se para o levantamento dos dados o Sistema desenvolvido pela Companhia de Processamento de Dados do Estado de São Paulo (PRODESP), em conformidade com o Sistema Informatizado Unificado de Gestão Arquivística de Documentos e Informação (SPDOC).

\subsection{Acessos aos documentos de maneira presencial}

Para que pudéssemos entrar no Arquivo Público do Estado de São Paulo, primeiro tivemos que passar pela recepção, local em que foi feito o cadastro de usuário com apresentação de um documento com foto, 
responder a um formulário no qual, o funcionário anotou em um sistema interno informações pessoais e então fez a entrega de crachá.

Para que tivesse acesso ao elevador, foi apresentado o crachá a uma funcionária e a catraca de acesso à área do elevador foi liberada, desta forma me encaminhei para o primeiro andar do prédio principal, para fazer a consulta que aconteceria no salão de consultas da torre principal do $1^{0}$ andar, onde se encontra o acervo Textual Permanente, composto de Fundos Públicos e Privado.

Ao chegar à sala de consultas, novamente uma catraca foi liberada com a apresentação do crachá, então, foi solicitado ao funcionário documentos referente ao Dossiê de Rubens Paiva e uma pesquisa no Fundo Júlio Prestes.

O funcionário me encaminhou a um terminal de computador onde pessoalmente preenchi novo formulário com meus dados pessoais (Nome, nacionalidade, data de nascimento, RG, órgão emissor, CPF, telefone, end. residencial, bairro, CEP, cidade, estado, país, e-mail e perfil que constava três alternativas: aluno, pesquisador ou professor).

Depois de tudo devidamente respondido, uma senha foi gerada que no meu caso foi PA 2015011030 (Ano, mês e horário da consulta).

Após encontrar no sistema o que procurava e solicitar ao funcionário tais documentos, fui informada de que Dossiê de Rubens Paiva, pertence ao Departamento de Ordem Social e Política (DEOPS), por essa razão, se fez necessário que eu assinasse um termo de responsabilidade de uso de informações.

Para qualquer outra pesquisa, ao acessar qualquer terminal de computadores, ao colocar a senha de acesso, aparecia no canto superior esquerdo meu nome como identificador de usuário.

Vale ressaltar que no salão de consulta há a presença de duas ou três pessoas fardadas entre ou usuários que fazem a segurança do material que está sendo consultado.

\subsection{Acessos aos documentos de maneira remota}

Como nosso intuito é verificar a privacidade do usuário com a aplicação do Framework para análise e comparação de estados de privacidade, também fizemos nossa pesquisa no site do Arquivo Público do Estado de São Paulo'.

Para a pesquisa de forma remota do material disponibilizado no site, não se faz necessário à identificação do usuário com seus dados pessoais, o que somente acontece quando este solicita uma informação através do menu Fale Conosco, nessa situação o usuário preenche uma ficha informando seu nome, seu e-mail, seu telefone, e o assunto (em que lhe é oferecido um menu com os assuntos determinados) e espaço para que escreva uma mensagem.

\footnotetext{
${ }^{1}$ Disponível em: <http://www.Arquivoestado.sp.gov.br/>. Acesso em: 15 mar. 2015.
} 
Após a pesquisa, como não encontramos nenhuma identificação aparente, recorremos ao sistema de levantamento de dados desenvolvido pela PRODESP.

A partir dos dados analisados verificamos nos históricos mensais, quais os dados referentes à identificação dos usuários eram levantadas pelo sistema e obtivemos as seguintes informações: número de visitas; número de páginas visitadas; porcentagens a partir do tempo que o usuário permanece no site; quais os três sistemas operacionais mais utilizados pelos usuários; qual Browser mais utilizado; qual a origem de conecção do usuário quando este está em um link buscador ou em um link de página externa, quais frases ou palavras que os usuários buscam na tentativa de encontrar respostas para suas necessidades informacionais.

Após a análise dos dados, verificou-se que, o site do Arquivo Público do Estado de São Paulo, em suas estatísticas não descreve a procedência do Protocolo de Internet - IP, que é o protocolo responsável pela a identificação das máquinas que utilizam o site, portanto não se sabe a procedência dos aparelhos que acessam o arquivo, isto é, o usuário tem sua privacidade preservada ao satisfazer suas necessidades informacionais quando seu acesso é feito de maneira remota.

\section{Aplicação do framework proposto por Rubel e Biava (2014)}

O framework para análise e comparação dos estados de privacidade, foi utilizado para que pudéssemos configurar a privacidade, que neste caso, foi analisada e comparada a privacidade dos usuários que procuram o arquivo Público do Estado de São Paulo, para satisfazer suas necessidades informacionais.

Assim, fizemos a seguinte representação.

$\boldsymbol{P}$ representa um usuário do Arquivo Público do Estado de São Paulo; O representam as informações sobre o usuário (seus dados pessoais, histórico familiar, tipo de consulta). $\boldsymbol{Q}$ representa Outras Pessoas.

Dessa maneira, tem se a relação de privacidade de acesso como: $\boldsymbol{a}$ POQ.

Assim, podemos usar as variáveis de alteração na tecnologia, e desta maneira, analisá-la com a diferença entre os registros em papel e registros digitalizados ou registros online.

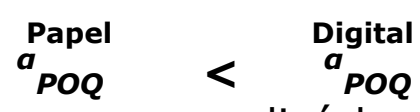

Nesse caso, ao analisá-lo a partir da diferença no tipo de registro, podemos obter diferentes resultados dependendo das variáveis feitas como, por exemplo:

a) Presencial

b)

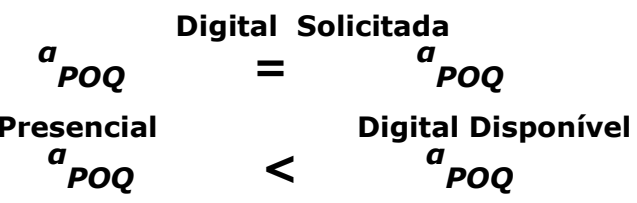


Na equação a, tanto o usuário que faz sua consulta de forma presencial como o que faz de maneira remota vão ter o mesmo grau de privacidade, visto que, ao fazer uma solicitação de acesso é necessária sua identificação, mesmo que seja solicitado o acesso aos documentos ostensivos, mas, por alguma razão tais documentos não estejam disponíveis no site.

Já na equação b, o usuário que optou para a consulta presencial, terá menor privacidade em relação ao usuário que faz a mesma consulta no mesmo documento, porém que está em formato digital e disponibilizado no site, pois, ao estar disponível a informação não vai ser preciso a identificação do usuário

Se alterarmos a variável tecnologia para a variável tempo, supondo que na era pré Internet $\left(T_{1}\right)$, o Arquivo Público do Estado de São Paulo, mantinha seus documentos em suportes de papel, estes só podiam ser solicitados e acessados pessoalmente, em seu espaço físico durante seu horário de atendimento. A partir de $2003\left(T_{2}\right)$ com a criação de seu site o Arquivo passou a disponibilizar seu acervo na ambiência digital e os documentos disponíveis puderam ser acessados e copiados gratuitamente por qualquer pessoa da comunidade.

Nesse cenário, acrescentar a variável de tempo $\left(\begin{array}{lll}T_{1} & \text { e } & T_{2}\end{array}\right)$ representando a relação geral de privacidade do usuário do arquivo à sua necessidade informacional com relação a outras pessoas:

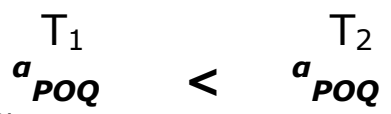

A equação acima compara a privacidade dos usuários no período pré Internet, com o período posterior a 2003. Considerando-se que o usuário sempre que procura o arquivo em questão preenche uma ficha com seus dados pessoais, para que a informação possa lhe ser entregue, concluímos que quando ele faz a busca no site e suas necessidades informacionais está disponível ele tem maior privacidade, visto que, o IP de sua máquina não é rastreado e não há identificação do usuário.

Nesse momento, devemos ressaltar que segundo informações em seu site, já são mais de quatrocentas mil imagens de documentos digitalizados disponíveis para consulta no site.

\section{Considerações finais}

O Arquivo Público do Estado de São Paulo ao disponibilizar uma parte de seu patrimônio documental em seu site está se adaptando ao ritmo das mudanças ocorridas, criando formas para que a busca, o acesso, o uso e o reuso do conteúdo digital suscite em um crescente interesse por parte dos usuários em se envolver com o patrimônio documental e facilitando a construção do conhecimento.

Norteados pela Lei de Acesso à Informação e pelo direito à privacidade, buscou-se através da proposição do Rubel e Biava (2014) do Framework para análise e comparação dos estados de privacidade, analisar o grau de privacidade dos usuários que procuram o Arquivo 
Público do Estado de São Paulo em seu espaço físico ou na ambiência digital para satisfazer suas necessidades informacionais.

Em concordância com os autores, verifica-se que a aplicação do framework, poderá contribuir para a construção de uma descrição quantificável de medidas de privacidade, pois, ainda que qualquer relação de privacidade possa ser descrita de maneira narrativa, ao optarmos por fazê-la somente dessa forma, corremos o risco de ignorar aspectos importantes nas relações de privacidade.

E ainda, que a formalização das relações de privacidade nos conduz a sermos mais precisos, desta maneira, tem-se a clareza sobre quem tem ou não privacidade; no domínio da informação se as pessoas têm ou não tem privacidade; qual relação entre pessoa ou pessoas a quem tem ou não tem privacidade e qual o tipo de privacidade que ela tem ou não tem, evitando desta forma ambiguidades. (RUBEL; BIAVA, 2014).

Verificamos que o Arquivo Público do Estado de São Paulo, faz o controle de acesso conforme recomendações da Associação Brasileira de Normas Técnicas (2005, p. 56), que sugere: "convém que as regras de controle de acesso e direitos para cada usuário ou grupos de usuários sejam expressas claramente na política de controle de acesso" para tanto, elaborou uma política de acesso que de acordo com a sugestão da Associação Brasileira de Normas Técnicas como pudemos perceber em nossa visita presencial, porém nosso objeto de estudo não é a segurança dos documentos arquivísticos custodiados pelo arquivo público e sim a análise e comparação da privacidade e dos estados de privacidade do usuário.

Como resultado da aplicação do Framework, sobre a análise e comparação de privacidade do usuário do Arquivo Público do Estado de São Paulo que o procura de maneira presencial ou remota para satisfazer suas necessidades informacionais o framework nos aponta que o usuário no momento posterior à 2003, em função da adoção de recursos digitais tem mais privacidade em seus acessos.

O Arquivo Público do Estado de São Paulo ao se fazer presente na ambiência digital e ao disponibilizar seu acervo na Web, não só amplia o conceito de custódia, como possibilita o acesso à informação a muitos cidadãos, que não teriam como fazer suas buscas e satisfazer suas necessidades informacionais de maneira presencial, devido às dificuldades de acesso, distância, custo e tempo, e ainda garante ao usuário de seu site o direito a preservação de sua privacidade.

Destaca-se que há um longo caminho a ser percorrido e o Arquivo Público do Estado de São Paulo inicia esse percurso disponibilizando o seu acervo documental e informacional na Web, a partir de uma prática que está considerando as possibilidades oferecidas pelas inúmeras formas de se fazer a mediação cultural e de promover o acesso ampliado às informações sem deixar de lado questões relevantes sobre a preservação da privacidade do seu usuário potencial. 


\section{Referências}

ALVARENGA, L. Representações do conhecimento na perspectiva da Ciência da Informação em tempo e espaços digitais. Revista Eletrônica de Biblioteconomia e Ciência da Informação, Rio de Janeiro, n.15, 2003. Disponível <http://www.encontrosbibli.ufsc.br/Edicao_15/alvarenga_representação.p df>. Acesso em: 15 nov. 2011.

ASSOCIAÇÃO BRASILEIRA DE NORMAS TÉCNICAS (ABNT). NBR ISO/IEC27 2002: tecnologia da informação - técnicas de segurança código de prática para a gestão da segurança da informação. Rio de Janeiro: ABNT, 2005. [Conteúdo técnico idêntico ao da ABNT NBR ISO/IEC 17799].

BELLOTTO, H. L. Archivística, archivos y documentos. São Paulo: Associação dos Arquivistas de São Paulo, 2005.

BRASIL. Presidência da República. Lei n. 8.159, de 8 de janeiro de 1991. Dispõe sobre a política nacional de arquivo público e privados e dá outras providências. Diário Oficial [da] Republica Federativa do Brasil, Brasília, DF, p. 455, 9 de janeiro de 1991. Disponível em: <http://www.conarq.arquivonacion alcional.gov.br/cgi/cgilua.exe/sys/ start.htm?from_info_index $=11$ \&infoid=100\&sid=52>. Acesso em: 14 jan. 2014.

BRASIL. Presidência da República. Lei no 12.527 , de 18 de novembro de 2011. Regula o acesso à informação previsto no inciso XXXIII do art. $5^{0}$ no inciso II do $\S 30$ do art.37 e no $\S 2$ do art. 216 da Constituição Federal; altera a Lei n. 8.112, de 11 de dezembro; revoga a Lei n.11.111, de 4 de maio de 2005, e dispositivos da Lei n. 8.159, de 8 de janeiro de 1991; e da outras providências. Diário Oficial [da] República Federativa do Brasil. Brasilia, DF, p.1, 18 de novembro de 2011. Edição extra. Disponível em: $<\quad$ http://www.planalto.gov.br/ccivil_03/_ato20112014/2011/lei/l12527.htm >. Acesso em: 8 Jun. 2012.

BRASIL. Presidência da República. Decreto no 7.724, de 16 de maio de 2012. Regulamenta a Lei no 12.527, de 18 de novembro de 2012, que dispõe sobre o acesso a informações. Diário Oficial [da] República Federativa do Brasil. Brasília, DF, 16 de maio de 2012. Seção 1. Disponível em: <http://www.conarq.arquivonacional.gov.br/cgi/cgilua.exe/sys/start.htm?i nfoid=772\&sid=54>. Acesso em: 8 Jun. 2012.

CASTELLS, M. A sociedade em rede. São Paulo: Paz e Terra, 1999.

CONSELHO NACIONAL DE ARQUIVOS (CONARQ). Diretrizes gerais para a construção de Websites de instituições arquivísticas. Rio de Janeiro, dez. $2000 . \quad$ Disponível em: <http://arquivonacional.gov.br/pub/virtual/diretrizes.htm>. Acesso em: 18 out. 2012. 
CONSELHO NACIONAL DE ARQUIVOS (CONARQ). Câmara técnica de documentos eletrônicos. Rio de Janeiro, ago. 2009. Disponível em: $<$ http://www.documentos

eletronicos.arquivonacional.gov.br/media/publicacoes/glossario/2009gloss ario_v5.0_final.pdf>. Acesso em: 15 mar. 2013.

GONÇALEZ, P. R. V. A. Disseminação da informação nos Websites das instituições do patrimônio público: um enfoque nos arquivos permanentes. 2013. 144f (Mestrado em Ciência da Informação) - Universidade Estadual Paulista "Júlio de Mesquita Filho", Faculdade de Filosofia e Ciência, Marília, 2013.

MARCONDES, C. H. Representação e economia da informação. Ciência da Informação, São Paulo, v. 30, n. 1, p. 61-70, jan./abr. 2001. Disponível em: <http://www.scielo.br/pdf/ci/v30n1/a08v30n1.pdf>. Acesso em: 22 maio 2011.

RUBEL, A. The particularized judgment account of privacy. Res Publica, n. 17, p. 275-290, 2011. Disponível em: <http://papers.ssrn.com/sol3/papers.cfm?abstract_id=978348>. Acesso em: 25 nov. 2014.

RUBEL, A.; BIAVA, R. A framework for analysing and comparing privacy states. Journal of the Association for Information Science and Tecnology, v. 65, n. 12, p. 2422-2431, 2014. Disponível em: <http://onlinelibrary.wiley.com/enhanced/doi/10.1002/asi.23138/>. Acesso em: 14 nov. 2014.

ROSENFELD, L. Information architecture: looking ahead. Journal of the American Society for Information Science and Technology, New York, v. 53, n.10, p. 874-87, 2002.

WERTHEIN, J.A sociedade da informação e seus desafios. Ciência da informação, Brasília, v. 29, n. 2, p. 71-77, maio/ago. 2000. 